\title{
Optimal Intergenerational Transfers: Public Education and Pensions
}

\section{CAMA Working Paper 58/2020 June 2020}

\section{Monisankar Bishnu}

Economics and Planning Unit, Indian Statistical Institute, Delhi Centre for Applied Macroeconomic Analysis, ANU

\section{Shresth Garg}

Department of Economics, Harvard University

\section{Tishara Garg}

Department of Economics, MIT

\section{Tridip Ray}

Economics and Planning Unit, Indian Statistical Institute, Delhi

\begin{abstract}
In presence of imperfections in education loan market, the standard policy response of intervening solely on education front, funded through taxes and transfers, necessarily hurts the initial working population. The literature suggests compensating them via payas-you-go pensions as a possible solution. But for various reasons sustainability of PAYG pensions is under serious doubt. We carry out the optimal policy exercise of a utilitarian government in a dynamically efficient economy with pension and education support obeying the Pareto criterion. We find that expansion of one instrument along with the other emerges as the optimal response, however, once the complete market level of education is achieved, the optimal policy suggests phasing pensions out. Eventually, government leads the economy to an equilibrium with zero pension and the Golden Rule level of education. This is achieved by exploiting only market opportunities without relying on other factors including human capital externalities, general equilibrium effects or sociopolitical factors.
\end{abstract}




\title{
Keywords
}

Public education, PAYG pension, intergenerational transfers, welfare state

\author{
JEL Classification
}

\section{Address for correspondence:}

(E) cama.admin@anu.edu.au

ISSN 2206-0332

The Centre for Applied Macroeconomic Analysis in the Crawford School of Public Policy has been established to build strong links between professional macroeconomists. It provides a forum for quality macroeconomic research and discussion of policy issues between academia, government and the private sector.

The Crawford School of Public Policy is the Australian National University's public policy school, serving and influencing Australia, Asia and the Pacific through advanced policy research, graduate and executive education, and policy impact. 


\title{
Optimal Intergenerational Transfers: Public Education and Pensions*
}

\author{
Monisankar Bishnu ${ }^{\dagger}$ \\ Tishara Garg§
}

\author{
Shresth Garg ${ }^{\ddagger}$ \\ Tridip Ray
}

\begin{abstract}
In presence of imperfections in education loan market, the standard policy response of intervening solely on education front, funded through taxes and transfers, necessarily hurts the initial working population. The literature suggests compensating them via pay-as-you-go pensions as a possible solution. But for various reasons sustainability of PAYG pensions is under serious doubt. We carry out the optimal policy exercise of a utilitarian government in a dynamically efficient economy with pension and education support obeying the Pareto criterion. We find that expansion of one instrument along with the other emerges as the optimal response, however, once the complete market level of education is achieved, the optimal policy suggests phasing pensions out. Eventually, government leads the economy to an equilibrium with zero pension and the Golden Rule level of education. This is achieved by exploiting only market opportunities without relying on other factors including human capital externalities, general equilibrium effects or socio-political factors.
\end{abstract}

Keywords: Public education; PAYG pension; intergenerational transfers; welfare state

${ }^{*}$ We thank Torben Andersen, Joydeep Bhattacharya, Shankha Chakraborty, V. V. Chari, Prabal Roy Chowdhury, Mausumi Das, Parikshit Ghosh, James Poterba, Morten Ravn, Debraj Ray, Arunava Sen, Joseph Stiglitz and Iván Werning for valuable comments and suggestions.

${ }^{\dagger}$ Economics and Planning Unit, Indian Statistical Institute, Delhi \& Centre for Applied Macroeconomic Analysis (CAMA), ANU. Email: mbishnu@isid.ac.in

${ }^{\ddagger}$ Department of Economics, Harvard University, Email: garg@g.harvard.edu

$\S$ Department of Economics, MIT, Email: tishara@mit.edu

IEconomics and Planning Unit, Indian Statistical Institute, Delhi Center. Email: tridip@isid.ac.in 


\section{Introduction}

Education loan market in most of the countries is far from perfect. Sometimes the market does not exist, or even when it does, it is extremely thin. Typically in this situation, the government appears as the rescuer with heavy education subsidy programs. ${ }^{1}$ While these subsidies are enjoyed in the early period of one's life, in many countries, individuals receive support in their old-age too, in the form of pension. In fact, education subsidy and Pay-As-You-Go (PAYG) pension are the two most significant support programs by governments around the world. ${ }^{2}$ Generally the working population is the only financer of these two transfers and their funds are channeled to two different generations. An education-pension policy package, with a forward intergenerational arm in the form of education subsidies and backward intergenerational arm of pension support, can be viewed as a double-armed policy of a welfare state.

A policy combination consisting of education subsidy and pension support is perceived as somewhat interlinked in nature. This idea of linking backward and forward intergenerational goods is not new. Becker and Murphy (1988) connects investment in education made by the parents with social security by considering this as a trade among generations: children receive education from their parents and in exchange pay for their old age benefit. Education investment is important to improve the labor productivity in future which will help sustain the social security program. Richman and Stagner (1986) also claims that the existence of PAYG pension incentivizes old investing in the younger cohorts. Pogue and Sgontz (1977) also had similar idea and informally argued in the context of social security taxation. In a seminal contribution, Boldrin and Montes (2005) formally show that one arm cannot sustain without the other. Any increase in education subsidy necessarily hurts the working population who pay for the increase but do not benefit from it themselves. This conflict is mitigated through interlinking education subsidies to old age income transfers, that is, pension is used to compensate agents who foot the bill for education subsidies. The authors establish that when credit market for education loans is missing, public education coupled with PAYG social security can actually replicate the complete market allocations (CMA), the laissez-faire allocation that is generated in the presence of a

\footnotetext{
${ }^{1}$ Government spending accounts for $91 \%$ of funds at primary, secondary and post-secondary levels and $70 \%$ at the tertiary level in OECD countries. Public education spending in the United States accounts for $4.2 \%$ of GDP and $11.8 \%$ of total public spending (see OECD (2017a)).

${ }^{2}$ OECD (2017b) report on public pensions states that 'Public pensions are often the largest single item of social expenditure, accounting for $18 \%$ of total government spending on average in 2013'. The old-age support expenditure, as a percentage of GDP in OECD countries stands at 8.6\%. Similarly, according to the report on education (OECD (2017a)) the education spending as percentage of total government spending is $11.3 \%$ and as a percentage of GDP is at $4.4 \%$.
} 
perfect loan market for education. Thus, an education-pension policy package can act as a substitute for the missing education loan market. According to Rangel (2003), backward intergenerational goods, such as social security, play a crucial role in sustaining investment in forward intergenerational goods like education.

However, over the years, while the intensity of education arm has increased, the PAYG pension program has come under serious budgetary pressure. ${ }^{3}$ In a host of developed countries, low fertility rate coupled with increased longevity of retired people have made this age-old intergenerational transfer program almost unsustainable (Whiteford and Whitehouse (2006) and OECD (2007)). Theoretically too, the classic Aaron-Samuelson result indicates that the PAYG pension program is welfare reducing in a dynamically efficient economy (Aaron (1966)) and is not warranted. ${ }^{4}$ But a policy package that calls for a education subsidy and pension forever (as also in Boldrin and Montes (2005)) cannot explain this intended fall of PAYG pensions. This is pointed out by Andersen and Bhattacharya (2017) who, in a model with human capital externalities, show that a rise and fall of pensions is desirable if the welfare state wants to secure education that is higher than the CMA level. In their model, pension rises to support the growing education subsidies and is phased out eventually with the help of intergenerational human capital externalities.

Surprisingly, the existing literature focuses only on some piecemeal aspects of the entire journey of this education-pension package. In fact this extensive literature is completely silent on the path of the package, focuses mainly only on a particular steady state. The only exception is Andersen and Bhattacharya (2017) who put emphasis on the path, however their interest lies in improving allocations when the market is already complete. Thus, the literature lacks in capturing the entire dynamics of this policy combination starting from an incomplete education loan market, the natural starting point to analyze government intervention. An analysis of a rich, complicated interactions and dependence dynamics among the instruments offered in a package starting from a scenario where loan market for education is far from perfect is therefore completely absent in the literature. Importantly, what is missing is the characterization of the policy path that is optimal for the benevolent government and, at the same time, is Pareto improving for all generations. Thus, in this paper, we consider the full-blown optimal policy exercise of a benevolent utilitarian government that maximizes the welfare of all the generations including the ones that are yet to

\footnotetext{
${ }^{3}$ For a nice discussion on the issues related to retirement security and age specific transfers, see Poterba (2014)

${ }^{4}$ Also see Samuelson (1975) and Blanchard and Fischer (1989).
} 
come. We take up the challenge of showing how this government can optimally complete an otherwise incomplete education loan market with the help of PAYG pensions and eventually achieves the best allocation (Golden Rule) following, in the process, the observed rise and fall of pensions ${ }^{5}$ and ensuring Pareto improvement for all generations.

Indeed, starting from an incomplete education loan market, we have been able to characterize the entire optimal path of the education-pension package. Interestingly, with respect to this optimal path, any policy recommendation of education subsidy and pension forever appears to be an 'interim' equilibrium. The economy with optimal policies actually moves away from the CMA over time. The optimality exercise finally secures an education level that is much higher than the CMA level of education. In this process, along the optimal path, pension initially rises and then falls. The rising pension path is observed until the economy reaches the CMA level of education. Pension support is disposed of gradually in finite time once CMA level of education is achieved and, eventually, education subsidy remains as the only working instrument of the policy package. Importantly, this phase-out is Pareto improving for all generations and we do not need to rely on any other external factors including externalities in human capital as in Andersen and Bhattacharya (2017). ${ }^{6}$ In our analysis, market imperfection itself is enough to generate the fall of pension and its eventual phase-out. The economy eventually converges to the Golden Rule.

In a dynamically efficient economy, ${ }^{7}$ securing an optimal policy where pension falls and is eventually phased out is an important feat in itself, especially when the Pareto constraint is not violated. ${ }^{8}$ For various reasons, including the demographic transition and related budgetary and political pressure, this age-old institution is under serious efficiency scanner. Major reforms towards downsizing the public pension benefits are

\footnotetext{
${ }^{5}$ See, for example, Bommier et al. (2010)

${ }^{6}$ Presence of such externalities is debatable (see, for example, Ciccone and Peri (2006), Acemoglu and Angrist (2000), Lange and Topel (2004), Yamarik (2008), and Rudd (2000)).

${ }^{7}$ Abel et al. (1989), show that the United States and other OECD countries are dynamically efficient. Given this, the relevant literature (including ours) assumes an environment with dynamic efficiency.

${ }^{8}$ While the literature in this area is sufficiently rich (for example, Breyer (1989), Friedrich and Straub (1993), Miles (1999), Sinn (2000), Lindbeck and Persson (2003) and Barr and Diamond (2006)), its broad conclusion is that when pay-as-you-go system is replaced by a funded system, it is generally impossible to compensate the first generation of pensioners for the loss incurred without making at least one later generation worse off than under PAYG.
} 
under consideration in many countries, including the Scandinavian countries. ${ }^{9}$ These include a transition from pure PAYG pension to a mix of PAYG and fully funded pension system, or even to a complete fully funded system. On theoretical grounds too, PAYG pension has little justification if the economy is dynamically efficient. Under dynamic efficiency, standard Aaron-Samuelson result indicates that pension should be phased out on pure efficiency grounds (see Aaron (1966)). In our analysis too, pension is eventually discontinued in finite time but only after playing a crucial role of completing an otherwise incomplete market and achieving the CMA level of education. ${ }^{10}$ Interestingly, this phase-out in our analysis happens without violating the Pareto criterion.

Let us now briefly explain the overall mechanism that is at work in our paper. While market imperfections can arise for various reasons, ${ }^{11}$ for tractability we model it in a simple way where imperfections create a wedge between the cost of borrowing for education and the return on savings. A government equipped with an educationpension policy package can access funds for education at the market rate of return by taxing today and returning the capitalized amount to the taxpayers in the future. Effectively, the government 'borrows' on behalf of the agents. ${ }^{12}$ This difference in costs makes publicly financed education cheaper to the extent that distortions created by taxation are lower than those in the credit market. This, along with the assumption that publicly and privately funded education are good enough substitutes in the production function for human capital, makes the case for replacing private funding by public funding for economies afflicted by market imperfections.

\footnotetext{
${ }^{9}$ Congressional Budget Office (2013) estimates that net transfers, defined as federal government transfers minus taxes, to households headed by a person over the age of 65 averaged 13,900 (in USD) whereas the corresponding transfers for non-elderly households with and without children were $-16,900$ (in USD) and $-15,800$ (in USD) respectively. It also reports that the 15 percent of households aged 65 and above received over 60 percent of the federal transfers (also see Poterba (2014)).

${ }^{10}$ We would like to mention here that the literature also finds that the general equilibrium effects (see, for example, Cooley and Soares (1999) and Boldrin and Rustichini (2000)) or some sociopolitical reasons (see Boldrin and Rustichini (2000) and Bishnu and Wang (2017)) are crucial in sustaining a social security system. In our analysis we refrain from these issues and focus only on the efficiency angle.

${ }^{11}$ These market imperfections could arise from well known sources of informational asymmetries such as moral hazard, adverse selection, imperfect enforcement, and so on, exacerbated, in general, due to the fact that human capital can not be pledged. See, for example, Friedman (1962), Nerlove (1975), Stiglitz and Weiss (1981), Galor and Zeira (1993) and Chapman (2006).

${ }^{12}$ We believe that the ability of the government to tax and therefore, effectively borrow from the middle-aged at the market rate of return is realistic and we do not use this in an arbitrary way: we insist on compensating all agents at every stage, so that the taxation power cannot be deployed with full impunity.
} 
A transition from private to public funding for without a system for compensating taxpayers necessarily hurts the initial working population who themselves did not benefit from the policy. This can be circumvented by providing old-age support to the agents who finance the public funding of education. In the literature, this is the idea behind pairing education subsidy with pension. However, in dynamically efficient economies, having PAYG pension in the steady state is welfare reducing. This problem is mitigated in our paper in the following way. The government gradually expands the public system, increasing the tax burden on the working population. For the intervention to be a Pareto improvement, we require that every generation be at least as well off with the intervention than without. Every generation must consume at least the non-intervention allocation. Pension is used to compensate the agents for their increased tax burden. Hence, pension payment and education subsidies go up until the marginal return from investment in education reaches the market rate of return which holds at the CMA. Once the CMA level of education is achieved, increased aggregate resources (due to the increased level of education) can come to play the compensatory role of pensions. Build up of these 'extra' resources allow pensions to be phased out in finite time. Interestingly, these extra resources are generated within the system, that is, without the help from any external sources such as human capital externalities. Even after pension is phased out, the social cost of investment in education for the government through intergenerational transfers still remains less than that for the agent under complete market. This difference in cost makes it optimal for the government to increase the investment in education beyond the complete market level. Eventually the economy reaches the Golden Rule, the steady state allocation that a social planner wants to achieve.

The rest of the paper is organized as follows. While section 2 outlines the model, the laissez-faire equilibrium is described in section 3. The government is introduced in section 4 , and section 5 sets up the optimal policy intervention exercise by the government. We characterize the optimal public policies in section 6 . Section 7 concludes. All the proofs are presented in the Appendix.

\section{The Model}

We consider an overlapping generations economy where agents live for three periods. They are young in the first period, middle-aged in the second and old in the third. Time is discrete and indexed by $t=-1,0,1,2, \ldots, \infty$. For simplicity we assume that there is no population growth with the size of each generation being normalized to 1 . 
In our notation, a generation is identified by the period of their old-age. That is, we call an agent as belonging to generation $t$ if she is old in period $t$. Thus a generation $t$ agent is young in period $t-2$ and middle aged in period $t-1$. In period $t-2$, young agents of generation $t$ borrow an amount $b_{t-2}$ in the credit market to invest in their education, $e_{t-2}$. The level of human capital $h$ is realized after one period of investment in education and is assumed to be a strictly increasing and strictly concave function of the investment in education. That means $e_{t-2}$ amount of investment made by a generation $t$ agent in period $t-2$ generates human capital $h_{t-1}=h\left(e_{t-2}\right)$ where $h^{\prime}()>$.0 and $h^{\prime \prime}()<$.0 . Throughout the paper we assume that this human capital production function is free from any externalities such as the parental level of education or the level of human capital of their cohorts in the economy. The factor prices are assumed to be exogenously given. ${ }^{13}$ In the second period of life in $t-1$, agents supply labor inelastically, earning an exogenous wage rate $w$ per unit of human capital. Once income is realized when they are middle-aged, agents repay their education loans taken when they were young.

For simplicity, we assume that agents consume only in the last period of their life. Agents save the entire net income $s_{t-1}$ on which they earn an exogenous gross interest $R>1$ when they are old. ${ }^{14}$ Consumption of generation $t$ agent who is old in period $t$ is denoted by $c_{t}$. Since agents consume only in their old age, the utility of a generation $t$ agent is given by $u\left(c_{t}\right) . u($.$) is assumed to be strictly increasing, strictly concave$ and it follows Inada conditions, that is, $u^{\prime}()>0,. u^{\prime \prime}()<$.0 with $\lim _{c \rightarrow 0} u^{\prime}(c)=\infty$ and $\lim _{c \rightarrow \infty} u^{\prime}(c)=0$. Agents are assumed to be non-altruistic; they maximize their own utility subject to the budget constraint.

An assumption that is maintained throughout this paper is that our economy is dynamically efficient. Theoretically, the Golden Rule level of capital is the level which maximizes the sum of utilities of all the generations at the steady state with equal weights assigned to all the generations. For any economy with a higher level of capital there exists a Pareto improvement which reduces the capital stock, and such economies are termed as 'dynamically inefficient'. For economies with lower level of capital, no such Pareto improvement is possible and these economies are called 'dynamically efficient'. Abel et al. (1989) generalize the notion of Golden Rule and

\footnotetext{
${ }^{13}$ The importance of general equlibrium effects for sustaining intergeneral transfers is well known in the literature (see, for example, Cooley and Soares (1999), Boldrin and Rustichini (2000), Poutvaara (2004), and Kothenburger and Poutvaara (2006). While focusing on the efficiency angle, we want to ensure that our results are not driven by the general equilibrium effects.

${ }^{14}$ Allowing consumption in the middle age, does not change the basic results. With exogenous factor prices, maximizing lifetime utility is equivalent to maximizing lifetime income which is independent of whether middle-age consumption is allowed.
} 
show that, according to the generalized notion, the US and other OECD countries are dynamically efficient. Thus, in line with the other studies in this literature, we assume that our economy is dynamically efficient.

\section{$3 \quad$ Laissez-faire Equilibrium}

\subsection{Incomplete Markets}

While market imperfections can be modeled in several ways, for simplicity and tractability we consider that the credit markets are characterized by imperfections driving the cost of borrowing for education $\rho$ above the market rate of return $R$, that is, $\rho>R .^{15}$ The borrowing cost $\rho$ increases with the degree of imperfection, with sufficiently large $\rho$ representing the complete absence of any education loan market.

Since there is no consumption in the first period and private borrowing is the only source of investment in education, total education expenditure equals private borrowing. An agent of generation $t$ solves the following problem:

$$
\begin{aligned}
& \max _{b_{t-2}, s_{t-1}} u\left(c_{t}\right), \\
& \text { subject to } \\
& 0 \leq b_{t-2} \leq \frac{w h\left(b_{t-2}\right)}{\rho}, \\
& s_{t-1}+\rho b_{t-2} \leq w h\left(b_{t-2}\right), \\
& c_{t} \leq R s_{t-1} .
\end{aligned}
$$

The first constraint, the no-default constraint, places an upper limit on the borrowings of the agent. The second and third constraints are the budget constraints for the middle and old age respectively.

The solution to problem (1) is characterized by: ${ }^{16}$

$$
\begin{gathered}
w h^{\prime}\left(e_{t-2}^{I M}\right)=\rho, \\
s_{t-1}^{I M}=w h\left(e_{t-2}^{I M}\right)-\rho e_{t-2}^{I M} .
\end{gathered}
$$

\footnotetext{
${ }^{15}$ These additional costs of borrowing can be justified in a setup where the lenders incur monitoring costs to ensure that borrowers do no run away as in Galor and Zeira (1993). Other market failures can also push the effective interest rate above the market interest rate (see, for example, Stiglitz and Weiss (1981)). This problem is even more severe in the market for education loans as, unlike physical capital, human capital is inalienable and cannot be mortgaged (see, for example, Friedman (1962), Nerlove (1975) and Chapman (2006)).

${ }^{16}$ Superscript $I M$ represents the solution for incomplete market.
} 
Agents invest in education up to the point where the marginal benefit of education, $w h^{\prime}\left(e_{t-2}^{I M}\right)$, is equal to the marginal cost, $\rho$. Given our structure, agents do not value their second-period consumption and consume everything in the last period of life, $c_{t}^{I M}=R\left(w h\left(e_{t-2}^{I M}\right)-\rho e_{t-2}^{I M}\right)$. This solution continues to hold period after period so that we drop the time subscript and define the incomplete markets allocation $\left(e^{I M}, c^{I M}\right)$ by $w h^{\prime}\left(e^{I M}\right)=\rho$, and $c^{I M}=R\left(w h\left(e^{I M}\right)-\rho e^{I M}\right)$. In the following subsection we compare this allocation with the complete markets benchmark.

\subsection{Complete Markets}

When the education loan market is complete and therefore there is no market failure, $\rho=R$. The allocation under this complete market is $\left(e^{C M}, c^{C M}\right)$ that satisfies $w h^{\prime}\left(e^{C M}\right)=R$ and $c^{C M}=R\left(w h\left(e^{C M}\right)-R e^{C M}\right)$. This allocation is called the Complete Markets Allocation (CMA).

Under incomplete markets, imperfections prevent investment in education from reaching the complete market level $e^{C M}$ given by $w h^{\prime}\left(e^{C M}\right)=R$, that is, $e^{I M}<e^{C M}$. Return on investment in education at the margin, $w h^{\prime}\left(e^{I M}\right)$, is strictly higher than the market rate of return $R$ since $w h^{\prime}\left(e^{I M}\right)=\rho>R$. Therefore a reallocation of resources towards investment in education can increase the total resource pie.

\section{The Government}

Market imperfections prevent consumption and investment in education from reaching the CMA level calling for a reallocation of resources towards education. In what follows we investigate whether state interventions can improve allocations and welfare. The government is a welfare state with a utilitarian objective, that is, it maximizes the discounted sum of generational utilities, with the discount factor $\beta$ reflecting social time preferences, ${ }^{17}$

$$
W=\sum_{t=1}^{\infty} \beta^{t} u\left(c_{t}\right), \quad 0<\beta<1 .
$$

The government can make intergenerational transfers using lump-sum taxes and subsidies. In particular, the government can tax the middle-aged, and use lump-sum

\footnotetext{
${ }^{17}$ Deriving the optimal public policies by maximizing the sum of discounted generational utilities is standard in the literature. For example, Docquier, Paddison, and Pestieau (2007) and Bishnu (2013) do so in the context of an economy with intergenerational education and pension transfers.
} 
transfers to subsidize education and old age consumption. The government has no other expenditure or sources of income. The government commits to the policy path announced.

When utilities of future generations are discounted, the notion of 'Golden Rule' accordingly is changed to that of 'modified Golden Rule', which is the level of capital that maximizes the discounted sum of utilities. The modified Golden Rule approaches Golden Rule, in the limit, as weight on future generations is increased to one $(\lim \beta \rightarrow 1)$. In an economy with production when there is no population growth (as in ours), it can be shown that the 'modified Golden Rule' level of capital is the one where the rate of return on capital $(R)$ is the same as the inverse of generational discount factor $(1 / \beta)$. In the under-accumulation (dynamically efficient) region that we are presently focusing on, the rate of interest is higher than the inverse of discount factor $(R>1 / \beta)$. For our analysis we assume that the same condition holds for our fixed rate of interest $R$.

Let $g_{t}, p_{t}$, and $\tau_{t}$ be the education subsidy, PAYG pensions and taxes for period $t$ respectively. The government balances its budget in every period, hence

$$
g_{t}+p_{t}=\tau_{t} \quad \forall t
$$

Total investment in education of generation $t$ agent who receives $g_{t-2}$ as education subsidies and borrows $b_{t-2}$ in the credit market is given by $e_{t-2}=g_{t-2}+b_{t-2}$. Since public and private education expenditures are perfect substitutes entering additively in the total education spending by the agent, public education crowds out private education one for one, and when $g_{t} \geq e^{I M}, b_{t}=0$ and $e_{t}=g_{t}$ for all $t \geq 1$.

In the presence of these fiscal instruments, a generation $t$ agent's optimization problem gets modified as follows:

$$
\begin{aligned}
& \max _{b_{t-2}, s_{t-1}} u\left(c_{t}\right), \\
& \text { subject to } \\
& 0 \leq b_{t-2} \leq \frac{w h\left(e_{t-2}\right)}{\rho}, \\
& s_{t-1}+\rho b_{t-2}+\tau_{t-1} \leq w h\left(e_{t-2}\right), \\
& c_{t} \leq R s_{t-1}+p_{t}, \\
& e_{t-2}=b_{t-2}+g_{t-2} .
\end{aligned}
$$


The argument in the human capital production function is total education expenditure which is the sum of education subsidies and private borrowing. The modified budget constraint for the middle-aged reflects that the burden of the total tax is borne by them. On the other hand, the old age budget constraint captures the additional source of income in the form of pension.

With these fiscal instrument, we first show that an one-arm policy is not implementable. A balance between the two policy arms is needed to achieve the CMA.

\section{Proposition 1.}

(a) A policy of providing only education subsidy to achieve the CMA necessarily hurts the initial middle-aged who at present pay the education tax for the future generation but did not receive any subsidy for their own education.

(b) A policy package consisting of education and pension can achieve the CMA: there exists a sequence of education subsidy, PAYG pensions and taxes $\left\{g_{t}, p_{t}, \tau_{t}\right\}_{t=1}^{\infty}$, which implements the CMA without hurting any generation. ${ }^{18}$

Proof. See Appendix A.

A policy of only education subsidy necessarily hurts the initial middle-aged who pay the education tax but do not receive any subsidy in return. To compensate them for this loss, we require some pensions to be paid to them in their old age. In Appendix A we show that when government implements the policy package where $g_{t}=e^{C M}$, $p_{t}=R e^{C M}$, and $\tau_{t}=e^{C M}+R e^{C M}$ for all $t$, the agents optimally choose $b_{t-2}=0$ and $s_{t-1}=w h\left(e^{C M}\right)-e^{C M}-R e^{C M}$ so that the resulting allocation is $\left(e^{C M}, c^{C M}\right)$, the CMA. ${ }^{19}$ This demonstrates that an education subsidy should be accompanied with a strictly positive pension benefit to achieve the CMA.

\section{Optimal Public Policies}

Observe that the policy package discussed above has positive PAYG pensions along with education subsidies for all $t$ to achieve the CMA. However it has been shown theoretically that in dynamically efficient economies, a positive PAYG pension is welfare reducing (Aaron (1966)). More importantly, many developed countries where PAYG pension exists in some form or the other are under serious budgetary pressure.

\footnotetext{
${ }^{18}$ These results are similar to those proven in Boldrin and Montes (2005).

${ }^{19}$ Note that when $g_{t-2}=e^{C M}$ and $b_{t-2}=0$, we get $e_{t-2}=e^{C M}$. Similarly when $s_{t-1}=$ $w h\left(e^{C M}\right)-e^{C M}-R e^{C M}$, we have $c_{t}=R\left(w h\left(e^{C M}\right)-e^{C M}-R e^{C M}\right)+p_{t}=R\left(w h\left(e^{C M}\right)-R e^{C M}\right)=$ $c^{C M}$.
} 
Demographic transition along with population aging is posing a serious threat to this age-old institution and has brought it under the efficiency scanner. However, a large body of research work devoted to the study of either dismantling or redesigning the pension program finds that doing so might have serious efficiency consequences.

But what is missing in the literature is how to improve the allocations under the incomplete market in an optimal public policy exercise of the government. In what follows, we carry out this optimization exercise of the utilitarian government and investigate whether the resulting optimal public policies can complete the incomplete education loan market with the help of PAYG pensions and eventually lead the economy reaching the Golden Rule. We also examine whether, along this process, the optimal pension path indeed satisfies the observed rise and (intended) fall of pensions.

Along an equilibrium path with government intervention, agents solve problem (2) taking the policy path $\left\{g_{t}, p_{t}, \tau_{t}\right\}_{t=1}^{\infty}$ as given. On the other hand, the utilitarian government solves the following optimization problem taking into account the agents' response to the policy instruments:

$$
\begin{aligned}
& \max _{\left\{g_{t}, p_{t}, \tau_{t}\right\}_{t=1}^{\infty}} W=\sum_{t=1}^{\infty} \beta^{t} u\left(c_{t}\right), \\
& \text { subject to } \\
& \tau_{t} \leq w h\left(e_{t-1}\right)-\rho b_{t-1} \quad \forall t, \\
& g_{t}+p_{t}=\tau_{t} \quad \forall t, \\
& g_{t} \geq 0 \quad \forall t \\
& p_{t} \geq 0 \quad \forall t
\end{aligned}
$$

The first constraint reflects that the maximum that can be taxed away from an individual is limited by the amount of resources available to her after repaying the education loan. The second one is budget balancing by the government. Combining these two we arrive at the following constraint

$$
g_{t}+p_{t} \leq w h\left(e_{t-1}\right)-\rho b_{t-1}
$$

which we refer to as the resource constraint. The third and fourth constraints are the non-negativity constraints on education subsidy and pensions respectively.

In addition, we impose the condition that the policy is Pareto improving for all generations, that is, utility of every generation under this policy is at least as high as that in its absence. This is captured by the following constraint which we refer to as 
the Pareto constraint ${ }^{20}$ :

$$
c_{t} \geq c^{I M} \quad \forall t
$$

Pension allows the initial generations, which contribute to the program but do not receive the benefit, to be compensated. However, if there is no Pareto constraint and the government places a sufficiently large weight on the utility of future generations, it may not fully compensate the initial generations. ${ }^{21}$ In that case, the initial generations may not participate in this program, stymieing its take-up. Thus, to ensure implementation, we allow the government to make only Pareto improvements.

For simplicity of exposition, we assume that in $t=1$ resources in the economy are sufficient to allow the government to raise, through taxation, at least the incomplete market level of investment in education $e^{I M} \cdot{ }^{22}$ We argue that this implies the government choosing $\left\{g_{t}, p_{t}, \tau_{t}\right\}_{t=1}^{\infty}$ such that $g_{t} \geq e^{I M}$ and the agents choosing $\left\{b_{t-2}, s_{t-1}\right\}_{t=1}^{\infty}$ such that $b_{t}=0$ is an equilibrium.

Given $g_{t} \geq e^{I M}$, the solution to the agent's problem is:

$$
\begin{gathered}
b_{t}=0 \quad \forall t \geq 1, \\
c_{1}=c^{I M}+p_{1}, \quad c_{2}=c^{I M}+\left[p_{2}-R\left(e_{1}+p_{1}\right)\right], \\
c_{t}=R\left(w h\left(e_{t-2}\right)-e_{t-1}-p_{t-1}\right)+p_{t} \quad \forall t \geq 3 .
\end{gathered}
$$

The optimization problem of the government is to maximize $W=\sum_{t=1}^{\infty} \beta^{t} u\left(c_{t}\right)$ subject to the agent's optimal choice, the resource constraint, the Pareto constraint, and the non-negativity constraints on education subsidy and pensions. Substituting

\footnotetext{
${ }^{20}$ While we set a lenient Pareto constraint of benchmarking only $c^{I M}$ as consumption, eventually a stringent requirement has been satisfied where consumption path is ever increasing.

${ }^{21}$ If the agents who gain form a policy change can compensate those who lose, maximizing the sum of utilities achieves the Pareto optimum. However, in an OLG setup, side payments among generations are not possible, necessitating the Pareto constraint.

${ }^{22}$ Our results go through even if we relax this assumption.
} 
(4), the problem reduces to:

$$
\max _{\left\{e_{t}, p_{t}\right\}_{t=1}^{\infty}} \sum_{t=1}^{\infty} \beta^{t} u\left(c_{t}\right)
$$

subject to

$e_{1}+p_{1} \leq w h\left(e^{I M}\right)-\rho e^{I M} ; \quad e_{t}+p_{t} \leq w h\left(e_{t-1}\right) \quad \forall t \geq 2, \quad$ [resource constraint]

$c_{t} \geq c^{I M} \quad \forall t \geq 1$

[Pareto constraint]

$e_{t} \geq 0 \quad \forall t \geq 1$

$p_{t} \geq 0 \quad \forall t \geq 1$

where consumption is as defined in (5). The optimal path that we characterize below has $g_{t} \geq e^{I M} \quad \forall t \geq 1$. Thus, $\left\{g_{t}, p_{t}, \tau_{t}\right\}_{t=1}^{\infty}$ and $\left\{b_{t-2}, s_{t-1}\right\}_{t=1}^{\infty}$ such that $b_{t}=0$ and $g_{t} \geq e^{I M} \quad \forall t \geq 1$ is indeed an equilibrium.

\subsection{A Feasible Path}

In this subsection, we show that the constraint set for problem (6) is non-empty. In particular, we show that there exists a feasible policy path which eventually reaches a steady state characterized by zero pensions and CMA level of investment in education $e^{C M}$. Along this steady state agents consume $R\left(w h\left(e^{C M}\right)-e^{C M}\right)>c^{C M}>c^{I M}$.

Proposition 2. There exists a sequence $\left\{g_{t}, p_{t}, \tau_{t}\right\}_{t=1}^{\infty}$ which satisfies the constraints of problem (6), and eventually reaches a steady state with CMA level of investment in education and zero-pension.

Proof. See Appendix B.

The feasible path shown in Appendix B is described as follows. Till we reach the steady state, we restrict the consumption of each generation to the minimum possible level $c^{I M}$. In the laissez-faire equilibrium, the agents were investing in education at a cost of $\rho>R$. The cost to the government for every unit of tax raised is only $R$ (assuming it compensates the taxed agents via pensions). This difference in costs allows the total resources in the economy to increase. This gain in resources is not passed on to the agents and the government keeps on reinvesting it till the CMA level of investment in education is achieved. Once it is achieved, this increased resources are used to phase out pensions. Once the steady state with zero pensions and CMA level of investment in education is reached, agents are allowed to have consumption strictly higher than $c^{I M}$. 
This feasible path also allows us to rule out some other paths from being optimal. Along this path, initial few generations are kept at $c^{I M}$ while generations along the steady state enjoy consumption strictly above $c^{I M}$. Any path along which all generations are at $c^{I M}$ throughout is clearly dominated by this path and hence cannot be the optimal. We use this observation later to rule out any such path from being optimal.

\subsection{Necessary Conditions for Optimality}

In Appendix C we show that an optimal policy path that solves problem (6) must satisfy the following first order conditions for all $t$ :

$$
\begin{gathered}
-\lambda_{t}+\psi_{t}-\beta R\left[u^{\prime}\left(c_{t+1}\right)+\eta_{t+1}\right]+\beta^{2} R w h^{\prime}\left(e_{t}\right)\left[u^{\prime}\left(c_{t+2}\right)+\eta_{t+2}\right]+\beta \lambda_{t+1} w h^{\prime}\left(e_{t}\right)=0 \\
u^{\prime}\left(c_{t}\right)-\beta R u^{\prime}\left(c_{t+1}\right)+\left(\eta_{t}-\beta R \eta_{t+1}\right)+\phi_{t}-\lambda_{t}=0
\end{gathered}
$$

Here $\lambda_{t}, \eta_{t}, \psi_{t}$ and $\phi_{t}$ are the non-negative Lagrange multipliers respectively for the resource constraint, Pareto constraint, and non-negativity constraints on education subsidy and pension. Equations (7) and (8) are the first order conditions with respect to education subsidy and pension respectively.

Condition (7) captures the trade-off between consumption and investment in education. If we ignore the multipliers for the moment, the condition boils down to $u^{\prime}\left(c_{t+1}\right)=\beta w h^{\prime}\left(e_{t}\right) u^{\prime}\left(c_{t+2}\right)$. Leaving a unit of consumption with the generation $t+1$ agent yields a marginal utility $u^{\prime}\left(c_{t+1}\right)$, while investing it in the education of generation $t+2$ agent yields $w h^{\prime}\left(e_{t}\right) u^{\prime}\left(c_{t+2}\right)$, which the planner discounts at the rate $\beta$. At the optimum, these two should be equal.

Condition (8) is the standard Euler equation. If we ignore the multipliers as before, the condition becomes $u^{\prime}\left(c_{t}\right)=\beta R u^{\prime}\left(c_{t+1}\right)$. Giving a unit of consumption to generation $t$ agent in the form of pension yields them a marginal utility $u^{\prime}\left(c_{t}\right)$, while leaving it with generation $t+1$, allowing it to be saved, yields $R u^{\prime}\left(c_{t+1}\right)$, which the planner discounts at the rate $\beta$. At the optimum, these two should be the same.

However, in general, all the Lagrange multipliers need not be zero at the same time. In what follows, we proceed to characterize optimal public policies as a solution to problem (6) under all possible scenarios. 


\section{Characterizing Optimal Public Policies}

We begin this section by establishing a few important results that go a long way towards characterizing optimal policy paths. Since these results are of some interest on their own, we present them as separate lemmas.

Lemma 1. If $p_{t}>0$, then $c_{t+1} \geq c_{t}$ for all $t$.

Proof. See Appendix D.1.

The Euler condition relates the marginal utility of consumption (and hence consumption) of two adjacent generations. With no constraints (that is, with all multipliers set to zero in equation (8)) the government wants to keep the consumption of every generation strictly higher than the previous generation. To implement that the government would like to reallocate resources away from generation $t$ to generation $t+1$ till the strict inequality is achieved.

However two constraints, the Pareto constraint and the non-negativity constraint on pension, limit its ability to do so. To improve the consumption of generation $t+1$ agent the planner can transfer resources between generations by reducing the pension payment by generation $t+1$ to generation $t$. If pension is already zero $\left(p_{t}=0\right)$, then the planner may not be able to carry out this reallocation to make $c_{t+1}$ strictly higher than $c_{t}$. Thus we require pensions in $t$ to be strictly positive $\left(p_{t}>0\right)$ to increase consumption in $t+1$. To understand why even with positive pensions we get weak inequality of consumption, we need to consider the Pareto constraint. If generation $t$ is already at the minimum level of consumption $\left(c^{I M}\right)$, then further reallocation of resources away from them is not feasible. In this situation we get the weak inequality as $c_{t+1} \geq c^{I M}=c_{t}$ (Pareto constraint on generation $t$ ).

Lemma 2. If resource constraints bind in any two consecutive periods $t-1$ and $t$ along with $p_{t}>0$, then $p_{t+1} \geq p_{t}$.

Proof. See Appendix D.2.

Let us consider two consecutive generations $t$ and $t+1$. From the expression of consumption $\left(c_{t+1}=R\left(w h\left(e_{t-1}\right)-e_{t}-p_{t}\right)+p_{t+1}\right)$, note that if the resource constraint binds for period $t$ then the only source of consumption for generation $t+1$ is the pensions they receive $\left(p_{t+1}\right)$. So if the resource constraints bind in periods $t-1$ and $t$, then consumption is the same as pension for generation $t$ and generation $t+1$. Now, 
if $p_{t}>0$ then using Lemma 1 it follows that $p_{t+1} \geq p_{t}$.

\section{Lemma 3.}

(a) If resource constraint binds for period t, then $e_{t} \leq e^{C M}$.

(b) If resource constraint does not bind for period t, then $e_{t} \geq e^{C M}$. Additionally, if $p_{t+1}>0$, then $e_{t}=e^{C M}$.

Proof. See Appendix D.3.

Suppose that the resource constraint binds for some period $t$, but $e_{t}>e^{C M}$, that is, $w h^{\prime}\left(e_{t}\right)<R$. We argue that there exists a profitable deviation to this policy. Binding resource constraint for period $t$ implies positive pension for generation $t+1$ as they do not save anything relying only on pension for consumption. Consider the policy where the government reduces $e_{t}$ by one and $p_{t+1}$ by $w h^{\prime}\left(e_{t}\right)$. The reduction in education tax is saved by generation $t+1$ increasing their earnings by $R$, while the lower pension support decreases their earning by $w h^{\prime}\left(e_{t}\right)$. The net effect on their consumption is positive since $R>w h^{\prime}\left(e_{t}\right)$. The decreased earning of generation $t+2$ due to lower education support is fully compensated via reduced pension burden. Thus, one generation is strictly better off without affecting any other generation.

Similarly, there exists a profitable deviation to the policy where $e_{t}<e^{C M}$ in some $t$ for which the resource constraint does not bind. Non-binding resource constraint implies positive savings for generation $t+1$. An additional unit of $e_{t}$ will increase the earnings of generation $t+2$ by $w h^{\prime}\left(e_{t}\right)$ which can be transferred to generation $t+1$ in the form of pension. The additional unit of tax decreases the earnings of generation $t+1$ (through foregone savings) by $R$. As $w h^{\prime}\left(e_{t}\right)>R$, this implies that this deviation increases the consumption of generation $t+1$ agent without affecting any other generation.

Additionally when $p_{t+1}>0$ and $e_{t}>e^{C M}$, reducing education subsidy to the young in $t$ by one unit and giving a relief to the middle-aged in the form of reduced taxes will decrease the earning of the young of $t$ by $w h^{\prime}\left(e_{t}\right)$ but increase the earnings through savings of the middle-aged by $R$. This income gain can in turn be transferred to the young by reducing their pension tax in the next period as $p_{t+1}>0$. Keeping $e_{t+1}$ unchanged, this deviation leads to a strict increase in the net earnings of the generation $t+2$ agents without affecting any other generation. 
Lemma 4. There exists a time period $Z \geq 2$ such that $p_{Z}=0$.

Proof. See Appendix D.4.

We have shown in section 5.1 that there exists a feasible path where the consumption of at least one generation is strictly above $c^{I M}$ while consumption of rest of the generations are weakly above $c^{I M}$. Hence, the path where the consumption is constant at $c^{I M}$ level cannot be optimal. This implies that there exists a period when the Pareto constraint does not bind.

Suppose pensions are positive throughout. Lemma 1 shows that government increases consumption in every period. Moreover, beyond the point where Pareto constraint stops binding, the multipliers on Pareto constraint in equation (8) drop out implying that the consumption, in fact, increases strictly. However, as we have shown in Lemma 3, positive pensions limit the education level weakly below $e^{C M}$. Hence, with positive pensions, consumption increases strictly without bound, while the resources in the economy stay limited, which gives us a contradiction.

\subsection{Completing the Incomplete Education Loan Market}

We first establish that optimal public policies complete the incomplete education loan market with the help of PAYG pensions.

\section{Proposition 3.}

(a) There exists some $T$ such that $e_{T} \geq e^{C M}$.

(b) Suppose $T^{*}$ is the first such period when $e_{t} \geq e^{C M}$. Then $e_{t-1} \leq e_{t}$ for all $t \leq T^{*}$, that is, education subsidy rises till period $T^{*}$.

Proof. See Appendix E.

Suppose $e_{t}<e^{C M}$ for all $t$. Then Lemma 3 implies that the resource constraint binds in all periods, leaving pensions as the only source of consumption for the agents. The government has to guarantee a consumption of at least $c^{I M}$ for each agent implying that it will have to give positive pensions in all periods. But we rule this out by Lemma 4 .

In the following subsection, we show that pension rises till period $T^{*} .{ }^{23}$ Since both education subsidy and pension tax increase from $T^{*}-1$ to $T^{*}$, total resources of the

\footnotetext{
${ }^{23}$ It should be noted from the proof of Proposition 4 in Appendix F that the argument for rise of pensions does not depend on the rise of education subsidies, that is, there is no circularity in our argument.
} 
economy must have increased between these two periods, implying a rise in education subsidy from $T^{*}-2$ to $T^{*}-1$. By a recursive argument, education subsidy increases monotonically till $T^{*}$.

In Proposition 5 below, we show that once investment in education achieves the complete market level $\left(e^{C M}\right)$, it does not fall below that level. Thus the optimal sequence of education subsidy, PAYG pensions and taxes completes the otherwise incomplete education loan market. Investment in education level of the economy rises monotonically throughout this process.

\subsection{Rise of Pensions}

Next we show that the government keeps on increasing pensions to support this rise in education subsidies.

Proposition 4. Suppose $T^{*}$ is as defined in Proposition 3. Then $p_{t-1} \leq p_{t}$ for all $t \leq T^{*}$, that is, along with education subsidy, pension also rises till period $T^{*}$.

Proof. See Appendix F.

Proposition 3(a) shows that there exists some $T$ in which education is above $e^{C M}$. $T^{*}$ is the first such $T$. Consider all the periods preceding $T^{*}$. Education is below $e^{C M}$ and by Lemma 3, we know that resource constraints bind in all these periods. Lemma 2, in turn, implies that pensions rise in this period.

\subsection{Fall and Phase Out of Pensions}

Once the complete market level of investment in education $e^{C M}$ is achieved, the government starts phasing out pension. In the following proposition, we show that the pension falls (strictly) after $T^{*}+1$ and reaches zero in finite time. During this period, education subsidy stays constant at the CMA level. Pension is phased out completely in finite time, that is, once it falls to zero it stays there forever.

\section{Proposition 5.}

(a) After $T^{*}+1$, pensions strictly fall till they become 0. During this period, education subsidy stays constant at $e^{C M}$.

(b) Suppose pension falls to zero in period $T^{*}+S$. Then for all $t \geq T^{*}+S$, the optimal solution has $p_{t}=0$. That is, pension program is completely phased out from period $T^{*}+S$ onwards. 
Proof. See Appendix G.

After reaching $e^{C M}$, there are enough resources in the economy for the government to keep education subsidy weakly above $e^{C M}$. However, a reasoning similar to that for Lemma 3 restrains the government from increasing education subsidy beyond $e^{C M}$ as long as pension remains positive. Hence education subsidy stays the same.

The optimal solution requires consumption to be increasing throughout. With constant investment in education, the only way to do so is via pension. Suppose the government increases pension for a generation at the expense of the next generation. In order to compensate the latter, a further increase in pension is required. This snowballs into an ever-increasing pension burden, making the path explode. The only way left is to reduce pension burden successively for each generation. Reducing pension burden is feasible after $T^{*}+1$ as generation $T^{*}+1$ is the first generation that makes positive savings in their middle age (in period $T^{*}$ ). Since agents now rely on both their pensions as well as positive savings for old age consumption, pensions need not track increasing consumption any more. Pension will be phased out by increasing agents' reliance on their own savings. Savings keep on increasing as pensions are phased out since agents' earnings net of education tax remain the same with a constant investment in education.

We make an interesting observation in the context of completing the education loan market optimally. An education-pension package with positive pensions forever is often recommended in the literature (see Proposition 1), cannot be optimal. Rather it is 'interim' in nature: it completes the education loan market, but itself is not an optimal solution. As optimality requires in a dynamically efficient economy, pension is phased out once $e^{C M}$ is achieved, without hurting any generation.

\subsection{The Long Run and the Golden Rule}

Finally we examine where the economy reaches in the long run. In the next proposition, we show that once pension is phased out in finite time, investment in education under the welfare state eventually reaches the Golden Rule.

Proposition 6. Suppose pension falls to zero in period $T^{*}+S$. Then for all $t \geq T^{*}+S$, the optimal solution has $e^{C M} \leq e_{t-1}<e_{t}<e^{G R}$ where $w h^{\prime}\left(e^{G R}\right)=1 / \beta$. Moreover, $\lim _{t \rightarrow \infty} e_{t}=e^{G R}$.

Proof. See Appendix H. 
The government has two instruments to mediate transfers between two subsequent generations, increasing education support and reducing pension. A unit taken from the previous generation has a social cost of $u^{\prime}\left(c_{t}\right)$ while it yields a social benefit of $\beta w h^{\prime}\left(e_{t}\right) u^{\prime}\left(c_{t+1}\right)$ if invested in education and $\beta R u^{\prime}\left(c_{t+1}\right)$ if used to reduce pension burden. The government equates the returns from these two channels. With diminishing returns in education, educational investment is kept constant at $e^{C M}$, and the government instead focuses on phasing pension out. However, once pension hits the zero lower bound, the only way left to mediate the transfer is via education. The social cost of investment in education is less than the private cost and hence the government expands education so long as this expansion is welfare increasing. In our setup, the welfare maximizing investment level in education is defined by the modified Golden Rule (MGR) where $w h^{\prime}\left(e^{G R}\right)=1 / \beta$ holds. ${ }^{24}$ Thus, in this process, the increase in investment in education is limited by the MGR level $e^{G R}$.

Note that the modified Golden Rule (MGR) level of investment in education is achieved when $w h^{\prime}\left(e^{G R}\right)=1 / \beta$ whereas the CMA level of investment in education $e^{C M}$ satisfies $w h^{\prime}\left(e^{C M}\right)=R$. At the MGR, the other condition that needs to be satisfied is $R=1 / \beta$. However, with fixed factor prices as in ours, there is no guarantee that this parametric condition actually holds. Since we assume $R>1 / \beta$ throughout the paper, by construction the economy can potentially move sufficiently close to the MGR but cannot touch it. Thus, after guaranteeing sufficiently higher level of investment in education than $e^{C M}$ and phasing out pension completely in finite time, we find that our economy reaches the MGR in the limit.

\subsection{Characterizing Optimal Public Policies: A Summary}

We summarize the optimal public policies that results as a solution to the welfare maximization exercise (problem (6)) of the utilitarian government. Throughout the analysis, the private education loan market remains incomplete. The benchmark consumption level in the Pareto constraint is set as the consumption under this incomplete market. This requirement is a bare minimum and easy to achieve, but eventually we satisfy a much harder constraint where consumption in each period is higher than the consumption in the previous period. We start implementing the optimal education-pension package from a period when loan market is incomplete, called period $t=1$ in our exercise.

\footnotetext{
${ }^{24}$ In our model, it can be shown that a planner who maximizes welfare through allocations would like to choose an allocation towards investment in education that satisfies $w h^{\prime}\left(e^{G R}\right)=1 / \beta$.
} 
We find that the optimal education-pension package can be characterized in three phases separated by periods $T^{*}$ and $T^{*}+S . T^{*}$ is the time period when the optimal education subsidy reaches the CMA level of investment in education; $e_{t}<e^{C M}$ for all $t<T^{*}$, and $e_{t} \geq e^{C M}$ for all $t \geq T^{*}$. On the other hand $T^{*}+S$ is the time period when optimal pension becomes zero for the first time; optimal pension is positive before $T^{*}+S$, and remains zero from $T^{*}+S$ onwards. In the first phase (periods 1 to $T^{*}$ ), both education subsidy and pension rise, the former reaching $e^{C M}$ in period $T^{*}$. In the second phase (periods $T^{*}$ to $T^{*}+S$ ), while education subsidy remains constant at $e^{C M}$, pension keeps falling till it becomes zero in period $T^{*}+S$. Finally, in the third phase (period $T^{*}+S$ onwards), pension remains at zero while education subsidy keeps increasing till it reaches the MGR level of investment in education in the limit.

Since investment in education is lower prior to implementation of the optimal policies, government increases education subsidy to increase resources of the economy. Till the CMA level of education is achieved in period $T^{*}$, government uses all the resources available in the economy making the resource constraint bind throughout this period. This policy leaves middle aged agents without any savings making them rely only on pension for consumption. A benevolent government in a dynamically efficient economy also increases (weakly) consumption over generations. To generate an increasing consumption path, the only option the government has is to choose an increasing pension path. Thus both components of the education-pension package rise till $T^{*}$. Once $e^{C M}$ is achieved, the economy generates enough resources such that the resource constraint stops binding and agents start saving. With the help of these savings, dependency on the pension component of the package starts to weaken. The pension arm is completely phased out in period $T^{*}+S$. When both the instruments of intergenerational transfer were available, the government was equating the social returns on the two. Now that the pensions hit the zero lower bound, education remains as the only working instrument. The social cost of investing in education is less than the private cost for the agent. Thus investment in public education starts increasing further from the CMA level, but this time it happens without any support from pension. The welfare state with only education arm then eventually reaches the MGR, the steady state that a social planner wants to achieve.

Our analysis confirms that a properly designed education-pension package not only completes the otherwise incomplete education loan market, it also leads the economy to the best possible allocation where pension is completely phased out. Interestingly, while the pension program is instrumental in the process of completing the education 
loan market, it is phased out once that objective is achieved. The optimal pension pattern follows rise and fall which is consistent with the empirical evidence.

\section{Conclusion}

A welfare state equipped with backward and forward intergenerational transfers emerges as a perfect rescuer in economies where education loan market is either primitive or missing. In fact, it can do a lot more. A double-armed welfare state is capable of leading the economy not only to the equilibrium that a perfect credit market generates (CMA), but also eventually to the one that the social planner finds to be the best (Golden Rule). This result has been shown in a full-blown exercise of a benevolent government that maximizes welfare of all the generations, while honoring the Pareto criterion and guaranteeing improvement in welfare over generations.

An education-pension policy package of the welfare state that we propose is powerful enough to take the economy to the CMA, but once this CMA is achieved, pension component of the package can be phased out optimally. Thus, in this analysis, the dual objective of completing the education loan market as well as phasing out PAYG pension emerges as an optimal choice of a utilitarian government. Both these objectives are very important and time relevant and interestingly, the optimal pension path that results from the analysis follows empirically observed rise and fall of PAYG pensions. While some piecemeal analyses of the entire journey have appeared in the literature, surprisingly the need for showing the entire voyage of the economy as an optimal choice of the government has somehow gone unnoticed. Our contribution lies precisely in filling up this significant void in the literature. 


\section{Appendix}

\section{A Proof of Proposition 1}

\section{A.1 Proof of Proposition 1(a)}

Proof. Consider problem (2). We ignore the no-default constraint for the time being. The optimal solution obtained indeed satisfies the constraint. Let $v_{1}$ and $v_{2}$ be the Lagrange multipliers for the constraint $0 \leq b_{t-2}$ and for the middle age budget constraint, respectively. Since the agents are not altruistic, they consume everything when they are old so that the old age budget constraint holds with equality. We substitute the two equality constraints into the objective function of the agent.

The Langrangian is given by

$$
\mathcal{L}=u\left(R s_{t-1}+p_{t}\right)+v_{1} b_{t-2}+v_{2}\left(w h\left(b_{t-2}+g_{t-2}\right)-s_{t-1}-\rho b_{t-2}-\tau_{t-1}\right) .
$$

Differentiating with respect to $b_{t-2}$ and $s_{t-1}$ we get

$$
\begin{gathered}
\frac{\partial \mathcal{L}}{\partial b_{t-2}}=v_{1}-v_{2}\left(\rho-w h^{\prime}\left(b_{t-2}+g_{t-2}\right)\right) \\
\frac{\partial \mathcal{L}}{\partial s_{t-1}}=u^{\prime}\left(c_{t}\right) R-v_{2}
\end{gathered}
$$

Setting both the equations equal to zero, we get the following first order conditions (along with the corresponding complementary slackness conditions):

$$
\begin{gathered}
v_{2}\left[\rho-w h^{\prime}\left(b_{t-2}+g_{t-2}\right)\right]=v_{1}, \\
u^{\prime}\left(c_{t}\right) R=v_{2} .
\end{gathered}
$$

Since $u^{\prime}\left(c_{t}\right)>0, v_{2}>0$, implying that the middle age budget constraint binds. That is, agents save their entire earnings net of tax payments and loan repayments.

Consider the case when the non-negativity constraint on borrowing binds, that is, $b_{t-2}=0$. By complementary slackness, we have $v_{1} \geq 0$. Since $v_{2}>0$, this implies that $\rho \geq w h^{\prime}\left(g_{t-2}\right)$. Thus, we have $g_{t-2} \geq e^{I M}$. It follows that whenever $g_{t-2}<e^{I M}$, we have $b_{t-2}>0$. This implies that $\rho=w h^{\prime}\left(b_{t-2}+g_{t-2}\right)$, or $b_{t-2}=e^{I M}-g_{t-2}$.

Hence, given $g_{t-2}$, the optimal borrowing and savings is given by: 


$$
\left(b_{t-2}, s_{t-1}\right)=\left\{\begin{array}{l}
\left(e^{I M}-g_{t-2}, w h\left(e^{I M}\right)-\rho\left(e^{I M}-g_{t-2}\right)-\tau_{t-1}\right) \quad \text { if } g_{t-2}<e^{I M} \\
\left(0, w h\left(g_{t-2}\right)-\tau_{t-1}\right) \quad \text { if } g_{t-2} \geq e^{I M} .
\end{array}\right.
$$

Consider the policy of providing only the education subsidy and no pensions starting from $t=1$. That is, $g_{t}>0$ and $p_{t}=0$ for all $t \geq 1$. This education subsidy is financed by taxing the working population, i.e $\tau_{t}=g_{t}>0$.

Consider the agent of generation 2 who is middle aged in period 1 . We call this the initial middle aged agent. Since $g_{0}=0$, from (A.1) we know that the agent responds to the policy by choosing $b_{0}=e^{I M}$. Hence, his savings and consumption with this policy are given by $s_{1}=w h\left(e^{I M}\right)-\rho e^{I M}-g_{1}$ and $c_{2}=R\left(w h\left(e^{I M}\right)-\rho e^{I M}-g_{1}\right)$. Note that since $g_{1}>0$ this $c_{2}$ is strictly less than $c^{I M}=R\left(w h\left(e^{I M}\right)-\rho e^{I M}\right)$. Thus, this policy necessarily hurts the middle aged.

\section{A.2 Proof of Proposition 1(b)}

Proof. Consider the policy $g_{t}=e^{C M}, p_{1}=0, p_{t+1}=R e^{C M}, \tau_{1}=e^{C M}$ and $\tau_{t+1}=$ $e^{C M}+R e^{C M}$ for all $t \geq 1$. Since $g_{t-2}>e^{I M}$, the optimal choice of generation $t \geq 3$ (given by equation (A.1)) is $b_{t-2}=0$ and $s_{t-1}=w h\left(e^{C M}\right)-e^{C M}-R e^{C M}$. Thus, for $t \geq 3, e_{t-2}=e^{C M}$ and the consumption becomes $c_{t}=R\left(w h\left(e^{C M}\right)-R e^{C M}\right)$, which is as under complete markets. Note that $c_{1}=c_{2}=c^{I M}$ under this policy, so that the policy does not hurt any generation.

\section{B Proof of Proposition 2}

Proof. We show that there exists a feasible policy path which eventually reaches a steady state characterized by zero pensions and CMA level of investment in education $e^{C M}$. Along this path, till reaching the zero pension steady state, we keep every generation at the incomplete market level of consumption $c^{I M}$. We define the policy path period by period.

Period 1: $p_{1}=0$ and $e_{1}=w h\left(e^{I M}\right)-\rho e^{I M}>e^{I M}$. Old agents in period 1 get no pension and stay at $c^{I M}$. The government taxes away all the income of middle-aged agents and uses it to fund education. Recall that, for ease of exposition, we have assumed that in period 1 resources available in the economy, wh( $\left.e^{I M}\right)-\rho e^{I M}$, are 
sufficient to allow the government to raise at least $e^{I M}$ in taxes.

Period 2: $p_{2}=c^{I M}$ and $e_{2}=w h\left(e_{1}\right)-c^{I M}$. We show that education strictly increases between periods 1 and 2. Note that the maximum of the function $w h(e)-R e$ is achieved at $w h^{\prime}\left(e^{C M}\right)=R$ and, for all $e<e^{C M}$, the function is increasing. As $e_{1}>e^{I M}$, we have

$$
\begin{aligned}
& w h\left(e_{1}\right)-R e_{1}>w h\left(e^{I M}\right)-R e^{I M}>w h\left(e^{I M}\right)-\rho e^{I M}=e_{1} \\
\Rightarrow & w h\left(e_{1}\right)-c^{I M}>e_{1} \quad\left[\text { since } c^{I M}=R\left(w h\left(e^{I M}\right)-\rho e^{I M}\right)=R e_{1}\right] \\
\Rightarrow & e_{2}>e_{1} .
\end{aligned}
$$

Similarly, for any period $t>1$ till education is below $e^{C M}$, the policy is defined as $p_{t}=c^{I M}$ and $e_{t}=w h\left(e_{t-1}\right)-c^{I M}$. Using $e_{2}>e_{1}$ it is easy to argue inductively that $e_{t+1}>e_{t}$, that is, as long as education is below $e^{C M}$, it keeps on increasing.

Moreover education increases at an increasing rate:

$$
\begin{aligned}
& w h\left(e_{t}\right)-w h\left(e_{t-1}\right)>w h^{\prime}\left(e_{t}\right)\left(e_{t}-e_{t-1}\right) \quad \text { [follows from concavity of } h(.) \text { ] } \\
& \Rightarrow w h\left(e_{t}\right)-w h\left(e_{t-1}\right)>e_{t}-e_{t-1} \quad\left[\text { since } w h^{\prime}\left(e_{t}\right)>R>1 \text { as } e_{t}<e^{C M}\right. \text { ] } \\
& \Rightarrow\left(w h\left(e_{t}\right)-c^{I M}\right)-\left(w h\left(e_{t-1}\right)-c^{I M}\right)>e_{t}-e_{t-1} \\
& \Rightarrow e_{t+1}-e_{t}>e_{t}-e_{t-1} \text {. }
\end{aligned}
$$

It follows that education reaches $e^{C M}$ in finite number of periods. Suppose education reaches $e^{C M}$ in some period $T$. From period $T+1$ onwards we keep $e_{t}$ at $e^{C M}$ and adjust pensions just enough to keep the consumption of previous generation at $c^{I M}$. We show that each generation will require less pension than the previous generation so that pensions can be phased out.

Since consumption is the sum of earning through savings and pensions, we define policies for periods $T+1$ and $T+2$ as follows.

Period T+1: $p_{T+1}=c^{I M}-R\left(w h\left(e_{T-1}\right)-e^{C M}-c^{I M}\right)$ and $e_{T+1}=e^{C M}$.

Period T+2: $p_{T+2}=c^{I M}-R\left(w h\left(e^{C M}\right)-e^{C M}-p_{T+1}\right)$ and $e_{T+2}=e^{C M}$. 
We show that pension falls between periods $T+1$ and $T+2$ :

$$
\begin{aligned}
& w h\left(e_{T-1}\right)-e^{C M}-c^{I M}<w h\left(e^{C M}\right)-e^{C M}-c^{I M}+R\left(w h\left(e_{T-1}\right)-e^{C M}-c^{I M}\right) \\
& \quad\left[\text { since } e_{T-1}<e^{C M} \text { and } e^{C M}+c^{I M} \leq w h\left(e_{T-1}\right) \text { by the resource constraint }\right] \\
\Rightarrow & c^{I M}-R\left(w h\left(e^{C M}\right)-e^{C M}-c^{I M}+R\left(w h\left(e_{T-1}\right)-e^{C M}-c^{I M}\right)\right)<c^{I M}-R\left(w h\left(e_{T-1}\right)-e^{C M}-c^{I N}\right. \\
\Rightarrow & p_{T+2}<p_{T+1} .
\end{aligned}
$$

Similarly, for any period $t>T+1$ the policy is defined as $p_{t}=c^{I M}-R\left(w h\left(e^{C M}\right)-\right.$ $\left.e^{C M}-p_{t-1}\right)$ and $e_{t}=e^{C M}$. Using $p_{T+2}<p_{T+1}$ it is easy to argue inductively that $p_{t+1}<p_{t}$, that is, pension keeps on falling.

Moreover pensions fall at an increasing rate. From the construction of pension in the falling pension region given above it follows that

$$
\begin{aligned}
& p_{t+1}-p_{t} \\
& =\left(c^{I M}-R\left(w h\left(e^{C M}\right)-e^{C M}-p_{t}\right)\right)-\left(c^{I M}-R\left(w h\left(e^{C M}\right)-e^{C M}-p_{t-1}\right)\right) \\
& =R\left(p_{t}-p_{t-1}\right) \\
& >p_{t}-p_{t-1} . \quad[\text { since } R>1]
\end{aligned}
$$

Thus pensions fall and reach zero in finite time. After pension falls to zero, we keep pensions at zero and education at $e^{C M}$ in all the following periods. Each generation consumes $R\left(w h\left(e^{C M}\right)-e^{C M}\right)>c^{I M}$ in the steady state.

Thus there exists a feasible policy path which reaches the CMA level of education and zero pension steady state.

\section{First Order Conditions for Problem (6)}

Let $\lambda_{t}, \eta_{t}, \psi_{t}$ and $\phi_{t}$ be the non-negative Lagrange multipliers respectively for the resource constraint, Pareto constraint, and non-negativity constraints on education subsidy and pension. 
The Lagrangian is given by

$$
\begin{aligned}
\mathcal{L}= & u\left(c^{I M}+p_{1}\right)+\beta u\left(c^{I M}+p_{2}-R\left(e_{1}+p_{1}\right)\right)+\sum_{t=3}^{\infty} \beta^{t-1}\left\{u\left(R\left(w h\left(e_{t-2}\right)-e_{t-1}-p_{t-1}\right)+p_{t}\right)\right\}+ \\
& \lambda_{1}\left[w h\left(e^{I M}\right)-\rho e^{I M}-e_{1}-p_{1}\right]+\sum_{t=2}^{\infty} \beta^{t-1}\left\{\lambda_{t}\left[w h\left(e_{t-1}\right)-e_{t}-p_{t}\right]\right\}+ \\
& \eta_{1} p_{1}+\beta \eta_{2}\left[p_{2}-R\left(e_{1}+p_{1}\right)\right]+\sum_{t=3}^{\infty} \beta^{t-1}\left\{\eta_{t}\left[R\left(w h\left(e_{t-2}\right)-e_{t-1}-p_{t-1}\right)+p_{t}-c^{I M}\right]\right\}+ \\
& \sum_{t=1}^{\infty} \beta^{t-1}\left\{\psi_{t} e_{t}+\phi_{t} p_{t}\right\} .
\end{aligned}
$$

Differentiating with respect to $e_{t}$ and $p_{t}$ gives us

$$
\begin{gathered}
\frac{\partial \mathcal{L}}{\partial e_{t}}=-\lambda_{t}+\psi_{t}-\beta R\left[u^{\prime}\left(c_{t+1}\right)+\eta_{t+1}\right]+\beta^{2} R w h^{\prime}\left(e_{t}\right)\left[u^{\prime}\left(c_{t+2}\right)+\eta_{t+2}\right]+\beta \lambda_{t+1} w h^{\prime}\left(e_{t}\right) \\
\frac{\partial \mathcal{L}}{\partial p_{t}}=u^{\prime}\left(c_{t}\right)-\beta R u^{\prime}\left(c_{t+1}\right)+\left(\eta_{t}-\beta R \eta_{t+1}\right)+\phi_{t}-\lambda_{t}
\end{gathered}
$$

Setting (C.1) and (C.2) equal to 0, along with the complementary slackness conditions, gives us the first order conditions, equations (7) and (8), in the text.

\section{Proofs of the Lemmas}

\section{D.1 Proof of Lemma 1}

Proof. As $p_{t}>0, \phi_{t}=0$ by complementary slackness condition. Then first order condition (8) becomes

$$
u^{\prime}\left(c_{t}\right)-\beta R u^{\prime}\left(c_{t+1}\right)+\left(\eta_{t}-\beta R \eta_{t+1}\right)-\lambda_{t}=0 .
$$

Note that $\eta_{t} \geq 0$ is the multiplier associated with the Pareto constraint $c_{t} \geq c^{I M}$. There are four cases to consider.

Case 1: $\eta_{t}>0$ and $\eta_{t+1}>0$. By complementary slackness both $c_{t}$ and $c_{t+1}$ are equal to $c^{I M}$, and hence $c_{t}=c_{t+1}$.

Case 2: $\eta_{t}>0$ and $\eta_{t+1}=0$. Then $c_{t}=c^{I M}$ and $c_{t+1} \geq c^{I M}$. Hence the required inequality holds. 
Case 3: $\eta_{t}=0$ and $\eta_{t+1}=0$. From the first order condition we get

$$
\begin{aligned}
& u^{\prime}\left(c_{t}\right)=\beta R u^{\prime}\left(c_{t+1}\right)+\lambda_{t} \\
\Rightarrow \quad & u^{\prime}\left(c_{t}\right)>u^{\prime}\left(c_{t+1}\right) \quad\left[\text { since } \beta R>1 \text { and } \lambda_{t} \geq 0\right] \\
\Rightarrow & c_{t+1}>c_{t} .
\end{aligned}
$$

Case 4: $\eta_{t}=0$ and $\eta_{t+1}>0$. It follows from the first order condition that

$$
\begin{aligned}
& u^{\prime}\left(c_{t}\right)=\beta R u^{\prime}\left(c_{t+1}\right)+\lambda_{t}+\beta R \eta_{t+1} \\
\Rightarrow & u^{\prime}\left(c_{t}\right)>u^{\prime}\left(c_{t+1}\right) \quad\left[\text { since } \beta R>1, \lambda_{t} \geq 0 \text { and } \eta_{t+1}>0\right] \\
\Rightarrow & c_{t+1}>c_{t} .
\end{aligned}
$$

But since $\eta_{t+1}>0, c_{t+1}=c^{I M}$ by complementary slackness condition. It follows that $c_{t}<c^{I M}$, a contradiction. Hence this case cannot arise.

Thus, in all the cases that can arise in the optimal solution, we have $c_{t+1} \geq c_{t}$ when $p_{t}>0$.

\section{D.2 Proof of Lemma 2}

Proof. Since $p_{t}>0$, from Lemma 1, we have $c_{t+1} \geq c_{t}$. Substituting the expressions for consumption in terms of education and pension we get

$$
\begin{aligned}
& c_{t+1} \geq c_{t} \\
\Rightarrow & R\left(w h\left(e_{t-1}\right)-e_{t}-p_{t}\right)+p_{t+1} \geq R\left(w h\left(e_{t-2}\right)-e_{t-1}-p_{t-1}\right)+p_{t} \\
\Rightarrow & p_{t+1} \geq p_{t} . \quad[\text { since resource constraints bind] }
\end{aligned}
$$

\section{D.3 Proof of Lemma 3}

Proof. Updating equation (8) by one period we get

$$
-\lambda_{t+1}+u^{\prime}\left(c_{t+1}\right)-\beta R u^{\prime}\left(c_{t+2}\right)+\left(\eta_{t+1}-\beta R \eta_{t+2}\right)+\phi_{t+1}=0 .
$$

Substituting this expression for $u^{\prime}\left(c_{t+1}\right)$ in equation (7), we get

$$
-\lambda_{t}+\psi_{t}+\beta\left(w h^{\prime}\left(e_{t}\right)-R\right)\left(\beta R u^{\prime}\left(c_{t+2}\right)+\beta R \eta_{t+2}+\lambda_{t+1}\right)+\beta R \phi_{t+1}=0 .
$$


Consider the case when the resource constraint binds in period $t$, that is, $e_{t}+p_{t}=$ $w h\left(e_{t-1}\right)$. This implies that $s_{t}=0$ and $c_{t+1}=p_{t+1}$. To ensure positive consumption (due to Inada condition), pension in period $t+1$ must be positive. Hence, $\phi_{t+1}=0$. Suppose, on the contrary, $e_{t}>e^{C M}(>0)$. This implies that $\psi_{t}=0$, and equation (D.1) becomes

$$
\beta\left(w h^{\prime}\left(e_{t}\right)-R\right)\left(\beta R u^{\prime}\left(c_{t+2}\right)+\beta R \eta_{t+2}+\lambda_{t+1}\right)=\lambda_{t} .
$$

Since the resource constraint binds, $\lambda_{t} \geq 0$. Since $\eta_{t+2} \geq 0, \lambda_{t+1} \geq 0$ and $u^{\prime}\left(c_{t+2}\right)>0$, we have $\beta R u^{\prime}\left(c_{t+2}\right)+\beta R \eta_{t+2}+\lambda_{t+1}>0$. This implies that $w h^{\prime}\left(e_{t}\right) \geq R$, or $e_{t} \leq e^{C M}$ which gives us the contradiction.

Now consider when the resource constraint does not bind in period $t$. Substituting for $\lambda_{t}=0$ in equation (D.1), we get

$$
\psi_{t}+\beta\left(w h^{\prime}\left(e_{t}\right)-R\right)\left(\beta R u^{\prime}\left(c_{t+2}\right)+\beta R \eta_{t+2}+\lambda_{t+1}\right)+\beta R \phi_{t+1}=0
$$

For the equality to hold, the second term must be non-positive (as $\phi_{t+1} \geq 0$ and $\left.\psi_{t} \geq 0\right)$. This in turn implies that $w h^{\prime}\left(e_{t}\right) \leq R$ resulting in $e_{t} \geq e^{C M}$.

Since $e_{t} \geq e^{C M}>0$, from complementary slackness, we get that $\psi_{t}=0$. Additionally, if $p_{t+1}>0$, then $\phi_{t+1}=0$. Since $\beta R u^{\prime}\left(c_{t+2}\right)+\beta R \eta_{t+2}+\lambda_{t+1}>0$, for $\phi_{t+1}$ to be zero we must have $w h^{\prime}\left(e_{t}\right)=R$, that is, $e_{t}=e^{C M}$.

\section{D.4 Proof of Lemma 4}

Proof. We prove this lemma by contradiction. Let us assume that $p_{t}>0$ for all $t \geq 2$. We consider the following exhaustive cases and argue that a contradiction arises in each.

Case 1: Consumption stays at $c^{I M}$ for all the generations. Discussion in section 5.1 shows that there exists a feasible path which dominates this path and hence this path cannot be an optimal one.

Case 2: Consumption is strictly above $c^{I M}$ for some $t$. There are two sub-cases to consider: Case 2(a): $p_{1}>0$ and Case 2(b): $p_{1}=0$.

Case 2(a): $p_{1}>0$. Since $c_{1}=c^{I M}+p_{1}$ (see equation (5)), with $p_{1}>0, c_{1}>c^{I M}$. As consumption is weakly rising, consumption stays above $c^{I M}$ for all subsequent 
periods. Consider the first order condition (8). The multipliers associated with the Pareto constraint, $\eta_{t}$, drop out. ${ }^{25}$ Then we manipulate condition (8) as follows:

$$
\begin{aligned}
& u^{\prime}\left(c_{t}\right)=\beta R u^{\prime}\left(c_{t+1}\right)+\lambda_{t} \\
\Rightarrow & \frac{u^{\prime}\left(c_{t}\right)}{u^{\prime}\left(c_{t+1}\right)}=\beta R+\frac{\lambda_{t}}{u^{\prime}\left(c_{t+1}\right)} \\
\Rightarrow & \frac{u^{\prime}\left(c_{t}\right)}{u^{\prime}\left(c_{t+1}\right)} \geq \beta R>1 \\
\Rightarrow & \frac{u^{\prime}\left(c_{t+1}\right)}{u^{\prime}\left(c_{t}\right)} \leq \frac{1}{\beta R}<1 .
\end{aligned}
$$

This implies that the sequence $\left\{u^{\prime}().\right\}$ is a contraction and converges to 0. By the Inada condition consumption converges to $\infty$. However, as the maximum possible consumption for any generation is bounded (by $\left.(R+1) w h\left(e^{C M}\right)\right)^{26}$, we have a contradiction.

Case 2(b): $p_{1}=0$. As $p_{1}=0, c_{1}=c^{I M}$. Therefore, the period for which consumption rises above $c^{I M}$ must be after 1 . Let that period be $k$. As pension is positive for all $t>1$, consumption rises and stays above $c^{I M}$ for all subsequent periods. The proof is then the same as the proof of Case 2(a) above.

As we get a contradiction in all the cases, pension cannot remain positive throughout. Hence there exists some period, after the first, where pension becomes zero.

\section{E Proof of Proposition 3}

\section{E.1 Proof of Proposition 3(a)}

Proof. Suppose not, that is, suppose that $e_{t}<e^{C M} \quad \forall t$. By Lemma 3 the resource constraint binds in all periods. This implies that, $c_{t}=R\left(w h\left(e_{t-2}\right)-e_{t-1}-p_{t-1}\right)+p_{t}=$ $p_{t}$ for all $t \geq 2$. On the other hand, the Pareto constraint requires that, in any $t$, $c_{t} \geq c^{I M}$. It follows that for all $t \geq 2, p_{t}=c_{t} \geq c^{I M}>0$, that is, pension in every period (after the first) is strictly positive. But this contradicts Lemma 4.

\footnotetext{
${ }^{25}$ The multipliers associated with constraints $p_{t} \geq 0$, that is, $\phi_{t}$, have already dropped out as we have started with the assertion that $p_{t}>0$ for all $t \geq 2$.

${ }^{26}$ In presence of positive pensions, lemma 3 implies that the maximum possible education for any generation is $e^{C M}$ irrespective of whether the resource constraint binds. Pension allows consumption to be transferred to the previous generation. Hence, the maximum possible consumption level of a generation is the earnings it and its next generation generate, giving the upper bound $\left(R w h\left(e^{C M}\right)+\right.$ $\left.w h\left(e^{C M}\right)=(R+1) w h\left(e^{C M}\right)\right)$
} 


\section{E.2 Proof of Proposition 3(b)}

Proof. In the proof of Proposition 4 in Appendix F below we establish that $p_{t-1} \leq p_{t}$ for all $2 \leq t \leq T^{*}$ (that is, $\left.p_{1} \leq p_{2} \leq \ldots \leq p_{T^{*}}\right){ }^{27}$ Since the resource constraint binds in all $t<T^{*}$, it follows from $p_{t-1} \leq p_{t}$ that $w h\left(e_{t-2}\right)-e_{t-1} \leq w h\left(e_{t-1}\right)-e_{t}$. For $t=T^{*}$, we have $w h\left(e_{T^{*}-2}\right)-e_{T^{*}-1}=p_{T^{*}-1} \leq p_{T^{*}} \leq w h\left(e_{T^{*}-1}\right)-e_{T^{*}}$. Shifting terms, we get $e_{T^{*}}-e_{T^{*}-1} \leq w h\left(e_{T^{*}-1}\right)-w h\left(e_{T^{*}-2}\right)$. Since $e_{T^{*}-1}<e^{C M}=e_{T^{*}}$, it follows that $w h\left(e_{T^{*}-1}\right)-w h\left(e_{T^{*}-2}\right)>0$ implying that $e_{T^{*}-2}<e_{T^{*}-1}$. Applying this argument recursively, we get that education is strictly rising till period $T^{*}$ (that is, $\left.e_{1}<e_{2}<\ldots<e_{T}^{*}\right)$.

\section{F Proof of Proposition 4}

Proof. As $T^{*}$ is the first such period when $e_{t} \geq e^{C M}$, education is strictly less than $e^{C M}$ for all the previous periods and, by Lemma 3, the resource constraints bind in all these previous periods. By a similar argument as in the proof of Proposition 3(a), we have pensions to be strictly positive in all $2 \leq t \leq T^{*}$. In particular, pension is strictly positive in period 2. Now applying Lemma 2, we can argue inductively that pensions rise from period 2 till period $T^{*}$. Also, note that the Pareto constraint for period $2, c_{2} \geq c^{I M}$, requires that $p_{2} \geq R\left(e_{1}+p_{1}\right)$, implying $p_{2} \geq p_{1}$. Hence, pension rises from period 1 till $T^{*}$.

\section{G Proof of Proposition 5}

\section{G.1 Proof of Proposition 5(a)}

Proof. From Lemma 4 we know that there exists a time period $Z>1$ such that $p_{Z}=0$. From Proposition 4 we know that pensions increase till period $T^{*}$. Let $T^{*}+S$ be the period where pensions become zero for the first time. In Step 1 below we first establish the path of strictly falling pensions assuming that the resource constraints do not bind for periods $T^{*}<t<T^{*}+S$. Then in Step 2 we show that the path of strictly falling pensions is indeed consistent with non-binding resource constraints.

Step 1: If the resource constraints do not bind for periods $T^{*}<t \leq T^{*}+S-1$, then pensions fall strictly between periods $T^{*}+1$ and $T^{*}+S$.

\footnotetext{
${ }^{27}$ Note that the argument for rise of pensions relies only on Lemmas 2 and 3 and not on the rise of education subsidies, that is, there is no circularity in our argument.
} 
Proof. Since $p_{T^{*}+k}, p_{T^{*}+k+1}, p_{T^{*}+k+2}>0$ for all $0 \leq k \leq S-3$, and the resource constraints do not bind, by Lemma 3 we know that $e_{T^{*}+k}=e^{C M}=e_{T^{*}+k+1}$ and $e_{T^{*}+k+2} \geq e^{C M}$. Moreover, $p_{T^{*}+k+2}>0$ implies that $c_{T^{*}+k+2} \leq c_{T^{*}+k+3}$ by Lemma 1 . Substituting the expressions for consumption in terms of education and pension we get

$$
\begin{aligned}
& c_{T^{*}+k+2} \leq c_{T^{*}+k+3} \\
\Rightarrow & R\left(w h\left(e_{T^{*}+k}\right)-e_{T^{*}+k+1}-p_{T^{*}+k+1}\right)+p_{T^{*}+k+2} \leq R\left(w h\left(e_{T^{*}+k+1}\right)-e_{T^{*}+k+2}-p_{T^{*}+k+2}\right)+p_{T^{*}+k+3} \\
\Rightarrow & R\left(p_{T^{*}+k+2}-p_{T^{*}+k+1}\right) \leq p_{T^{*}+k+3}-p_{T^{*}+k+2}-R\left(e_{T^{*}+k+2}-e^{C M}\right)
\end{aligned}
$$

[since $\left.e_{T^{*}+k}=e^{C M}=e_{T^{*}+k+1}\right]$

$\Rightarrow R\left(p_{T^{*}+k+2}-p_{T^{*}+k+1}\right) \leq p_{T^{*}+k+3}-p_{T^{*}+k+2} . \quad\left[\right.$ since $\left.e_{T^{*}+k+2} \geq e^{C M}\right]$

Suppose $p_{T^{*}+k+2} \geq p_{T^{*}+k+1}$. This implies that $p_{T^{*}+k+3} \geq p_{T^{*}+k+2}$, and hence $p_{T^{*}+k+3}>0$. By a recursive argument, $S$ gets pushed to infinity and the pensions never become zero. This is a contradiction to Lemma 4 . Hence $p_{T^{*}+k+2}<p_{T^{*}+k+1}$ for all $0 \leq k \leq S-3$, that is, pensions fall strictly between periods $T^{*}+1$ and $T^{*}+S-1$. Since $p_{T^{*}+S-1}>0$ and $p_{T^{*}+S}=0$, it follows that pensions fall strictly between periods $T^{*}+1$ and $T^{*}+S$.

Step 2: The path of strictly falling pensions derived in Step 1 is consistent with the non-binding resource constraints.

Proof. We know that the resource constraint does not bind in period $T^{*}$, that is, $e_{T^{*}}+p_{T^{*}}<w h\left(e_{T^{*}-1}\right)$. We first show that the resource constraint does not bind for period $T^{*}+1$.

Since $p_{T^{*}+1}>0$, by Lemma 1 we have $c_{T^{*}+2} \geq c_{T^{*}+1}$. It follows that

$$
\begin{aligned}
& c_{T^{*}+2} \geq c_{T^{*}+1} \\
\Rightarrow & R\left(w h\left(e_{T^{*}}\right)-e_{T^{*}+1}-p_{T^{*}+1}\right)+p_{T^{*}+2} \geq R\left(w h\left(e_{T^{*}-1}\right)-e_{T^{*}}-p_{T^{*}}\right)+p_{T^{*}+1} \\
\Rightarrow & R\left(w h\left(e_{T^{*}}\right)-e_{T^{*}+1}-p_{T^{*}+1}\right) \geq R\left(w h\left(e_{T^{*}-1}\right)-e_{T^{*}}-p_{T^{*}}\right)+\left(p_{T^{*}+1}-p_{T^{*}+2}\right) \\
\Rightarrow & R\left(w h\left(e_{T^{*}}\right)-e_{T^{*}+1}-p_{T^{*}+1}\right)>R\left(w h\left(e_{T^{*}-1}\right)-e_{T^{*}}-p_{T^{*}}\right) \quad \text { [since } p_{T^{*}+1}>p_{T^{*}+2} \text { by Step 1] } \\
\Rightarrow & \left.w h\left(e_{T^{*}}\right)-e_{T^{*}+1}-p_{T^{*}+1}>0, \quad \text { [since the resource constraint does not bind in period } T^{*}\right]
\end{aligned}
$$

that is, the resource constraint does not bind for period $T^{*}+1$.

Proceeding recursively as above, using in each step the non-binding resource constraint of the earlier period and strictly falling pensions between two consecutive 
periods, it is easy to see that the resource constraints do not bind for periods $T^{*}+1$ to $T^{*}+S-1$. Thus the path of strictly falling pensions is indeed consistent with the non-binding resource constraints assumed in Step 1.

Combining Steps 1 and 2 we conclude that pensions fall strictly between periods $T^{*}+1$ and $T^{*}+S$. Also, since the resource constraints do not bind for periods $T^{*}$ to $T^{*}+S-1$ while the pensions are strictly positive, it follows from Lemma 3 that education remains constant at $e^{C M}$ from $T^{*}$ to $T^{*}+S-2$. This completes the proof of Proposition 5(a).

\section{G.2 Proof of Proposition 5(b)}

Proof. Similar to the proof of Proposition 5(a), we proceed in two steps. In Step 1, we prove that pension program is completely phased out from period $T^{*}+S$ onwards by assuming that the resource constraint does not bind from period $T^{*}+S$ onwards. Then in Step 2, we verify that zero pensions are consistent with non-binding resource constraints during this period.

Step 1: If the resource constraints do not bind for periods $t \geq T^{*}+S$, then $p_{t}=0$ $\forall t \geq T^{*}+S$.

Proof. We know that $p_{T^{*}+S}=0$. Suppose that $p_{T^{*}+S+1}>0$. Since the resource constraint does not bind for period $T^{*}+S$, this implies that $e_{T^{*}+S}=e^{C M}$ (by Lemma 3) and $c_{T^{*}+S+2} \geq c_{T^{*}+S+1}$ (by Lemma 1). Substituting the expressions for consumption, we get

$$
\begin{aligned}
& c_{T^{*}+S+2} \geq c_{T^{*}+S+1} \\
\Rightarrow & R\left(w h\left(e_{T^{*}+S}\right)-e_{T^{*}+S+1}-p_{T^{*}+S+1}\right)+p_{T^{*}+S+2} \geq R\left(w h\left(e_{T^{*}+S-1}\right)-e_{T^{*}+S}-p_{T^{*}+S}\right)+p_{T^{*}+S+1} \\
\Rightarrow & p_{T^{*}+S+2}-p_{T^{*}+S+1} \geq R\left(e_{T^{*}+S+1}-e^{C M}+w h\left(e_{T^{*}+S-1}\right)-w h\left(e^{C M}\right)+p_{T^{*}+S+1}\right) . \\
& {\left[\text { since } e_{T^{*}+S}=e^{C M}, \text { and } p_{T^{*}+S}=0\right] }
\end{aligned}
$$

The RHS is strictly positive because $e_{T^{*}+S-1}, e_{T^{*}+S+1} \geq e^{C M}$ (by Lemma 3), and $p_{T^{*}+S+1}>0$. Hence pensions increase between periods $T^{*}+S+1$ and $T^{*}+S+2$. By a recursive argument pensions increase forever and never becomes zero, which is a contradiction to Lemma 4. This implies that $p_{T^{*}+S+1}=0$. By a similar argument $p_{t}=0 \forall t \geq T^{*}+S$.

Step 2: The path of zero pensions derived in Step 1 is consistent with the non-binding resource constraints for periods $t \geq T^{*}+S$. 
Proof. Since by Step 1 pensions are zero from period $T^{*}+S$ onwards, we have, for $t \geq T^{*}+S+1, c_{t}=R\left(w h\left(e_{t-2}\right)-e_{t-1}\right)$ which is strictly positive throughout as the Pareto constraint guarantees that $c_{t} \geq c^{I M}>0$. It follows that the resource constraints do not bind for $t \geq T^{*}+S$.

Combining Steps 1 and 2, the proof of Proposition 5(b) is completed.

\section{H Proof of Proposition 6}

Proof. We proceed in four steps. In the first two steps, we proceed under the assumption that the Pareto constraint does not bind from period $T^{*}+S+1$ onwards. In the third step, we show that the resulting solution path is consistent with this assumption. Finally, in the fourth step we show that education approaches the Golden Rule level in the limit.

Step 1: If the Pareto constraint does not bind for periods $t \geq T^{*}+S+1$, then $\beta w h^{\prime}\left(e_{t}\right)>1 \forall t \geq T^{*}+S-1$.

Proof. Suppose that $\beta w h^{\prime}\left(e_{T^{*}+S-1}\right) \leq 1$. We know from the proof of Proposition (5) above that the resource constraint stops binding after period $T^{*}$. Consider the first order condition (7) for $t=T^{*}+S-1$ (using $\lambda_{T^{*}+S-1}, \lambda_{T^{*}+S}=\eta_{T^{*}+S+1}=\psi_{T^{*}+S-1}=0$ due to complementary slackness):

$$
\begin{array}{lll} 
& -\beta R\left[u^{\prime}\left(c_{T^{*}+S}\right)+\eta_{T^{*}+S}\right]+\beta^{2} R w h^{\prime}\left(e_{T^{*}+S-1}\right)\left[u^{\prime}\left(c_{T^{*}+S+1}\right)\right]=0 \\
\Rightarrow & u^{\prime}\left(c_{T^{*}+S}\right)+\eta_{T^{*}+S}=\beta w h^{\prime}\left(e_{T^{*}+S-1}\right)\left(u^{\prime}\left(c_{T^{*}+S+1}\right)\right) \\
\Rightarrow & u^{\prime}\left(c_{T^{*}+S}\right) \leq \beta w h^{\prime}\left(e_{T^{*}+S-1}\right)\left(u^{\prime}\left(c_{T^{*}+S+1}\right)\right) \quad\left[\text { since } \eta_{T^{*}+S} \geq 0\right] \\
\Rightarrow & c_{T^{*}+S} \geq c_{T^{*}+S+1} . \quad\left[\text { since } \beta w h^{\prime}\left(e_{T^{*}+S-1}\right) \leq 1, \text { and } u^{\prime \prime}(.)<0\right]
\end{array}
$$

Substituting the expressions for consumption we get

$$
\begin{aligned}
& c_{T^{*}+S} \geq c_{T^{*}+S+1} \\
\Rightarrow & R\left(w h\left(e_{T^{*}+S-2}\right)-e_{T^{*}+S-1}-p_{T^{*}+S-1}\right)+p_{T^{*}+S} \geq R\left(w h\left(e_{T^{*}+S-1}\right)-e_{T^{*}+S}-p_{T^{*}+S}\right)+p_{T^{*}+S+1} \\
\Rightarrow & e_{T^{*}+S}-e_{T^{*}+S-1} \geq\left[w h\left(e_{T^{*}+S-1}\right)-w h\left(e_{T^{*}+S-2}\right)\right]+p_{T^{*}+S-1} \quad\left[\text { since } p_{T^{*}+S}, p_{T^{*}+S+1}=0\right] \\
\Rightarrow & e_{T^{*}+S}-e_{T^{*}+S-1}>0 . \quad\left[\text { since } e_{T^{*}+S-1} \geq e^{G R}>e^{C M}=e_{T^{*}+S-2}, \text { and } p_{T^{*}+S-1}>0\right]
\end{aligned}
$$

Thus education strictly increases between $T^{*}+S-1$ and $T^{*}+S$ which in turn implies that $\beta w h^{\prime}\left(e_{T^{*}+S}\right)<1$. By a recursive argument, it can be shown that education increases forever and consumption falls forever. 
Now, consider a (feasible) deviation from this path where $e_{t}=e_{t+1}=e_{T^{*}+S-1}$ $\forall t \geq T^{*}+S-1$. It is easy to see that this deviation strictly dominates the original path as consumption increases between $T^{*}+S$ and $T^{*}+S+1$ stays constant at a higher level from $T^{*}+S+1$ onwards, instead of falling. Hence the original path cannot be optimal, implying that $\beta w h^{\prime}\left(e_{T^{*}+S-1}\right)>1$. By a similar argument it can be shown that $\beta w h^{\prime}\left(e_{t}\right)>1 \forall t \geq T^{*}+S-1$.

Step 2: If the Pareto constraint does not bind for periods $t \geq T^{*}+S+1$, then $c_{t+1}>c_{t}$, and $e_{t}>e_{t-1} \forall t \geq T^{*}+S$.

Proof. Under the assumption of non-binding Pareto constraint (the resource constraint is non-binding, as proved above), the first order condition (7) becomes

$$
u^{\prime}\left(c_{t+1}\right)=\beta w h^{\prime}\left(e_{t}\right) u^{\prime}\left(c_{t+2}\right) \quad \forall t \geq T^{*}+S
$$

Then $c_{t+1}>c_{t}$ follows from this revised first order condition and Step 1.

Expanding $c_{T^{*}+S+2}>c_{T^{*}+S+1}$ (note that pensions are zero from period $T^{*}+S$ onwards) we get

$$
\begin{gathered}
w h\left(e_{T^{*}+S}\right)-e_{T^{*}+S+1}>w h\left(e_{T^{*}+S-1}\right)-e_{T^{*}+S} \\
\Rightarrow w h\left(e_{T^{*}+S}\right)-w h\left(e_{T^{*}+S-1}\right)>e_{T^{*}+S+1}-e_{T^{*}+S} .
\end{gathered}
$$

Suppose education falls, that is, the LHS is weakly negative. This implies that the RHS is strictly negative. By a recursive argument, education keeps on falling. Moreover, concavity of education production function along with $w h^{\prime}()>$.1 implies that the rate of fall is increasing. This contradicts Lemma 3 which ensures that education stays above $e^{C M}$ when the resource constraint does not bind. Therefore we must have $e_{T^{*}+S}>e_{T^{*}+S-1}$. A similar argument shows that $e_{t}>e_{t-1} \forall t \geq T^{*}+S$.

Step 3: The Pareto constraint does not bind for periods $t \geq T^{*}+S+1$ along the path derived in Steps 1 and 2.

Proof. From Step 2 we know that consumption increases strictly from period $T^{*}+S$. Hence, the Pareto constraint does not bind from $T^{*}+S+1$.

Step 4: Education approaches the Golden Rule level in the limit, that is, $\lim _{t \rightarrow \infty} e_{t}=$ $e^{G R}$. 
Proof. We know that the Pareto constraint and the resource constraint stop binding after period $T^{*}+S+1$. Then the first order condition (7) becomes

$$
\frac{u^{\prime}\left(c_{t+1}\right)}{u^{\prime}\left(c_{t+2}\right)}=\beta w h^{\prime}\left(e_{t}\right) \quad \forall t \geq T^{*}+S+1
$$

The sequence of $e_{t}$ is monotonically increasing and bounded, hence convergent. By continuity, the sequences of consumption and marginal utilities are also convergent. The left hand side of the equation above converges to 1 . Therefore, $\beta w h^{\prime}\left(e_{t}\right)$ approaches 1 , that is, $e_{t}$ converges to $e^{G R} \cdot{ }^{28}$

Combining Steps 1, 2, 3 and 4, the proof of Proposition 6 is completed.

\footnotetext{
${ }^{28}$ Note that, with convergent consumption and non-binding resource and Pareto constraints, first order condition (8) implies zero pensions, hence verifying our result.
} 


\section{References}

Aaron, Henry (1966). "The Social Insurance Paradox". In: The Canadian Journal of Economics and Political Science 32.3, pp. 371-374.

Abel, Andrew B et al. (1989). "Assessing Dynamic Efficiency: Theory and Evidence". In: Review of Economic Studies 56.1, pp. 1-20.

Acemoglu, Daron and Joshua Angrist (2000). "How Large Are Human-Capital Externalities? Evidence from Compulsory Schooling Laws". In: NBER Macroeconomics Annual 15, pp. 9-59.

Andersen, Torben M. and Joydeep Bhattacharya (2017). "The Intergenerational Welfare State and the Rise and Fall of Pay-as-you-go Pensions". In: Economic Journal 127.602, pp. 896-923.

Barr, Nicholas and Peter Diamond (2006). "The Economics of Pensions". In: Oxford Review of Economic Policy 22.1, pp. 15-39.

Becker, Gary S and Kevin M Murphy (1988). "The Family and the State". In: Journal of Law and Economics 31.1, pp. 1-18.

Bishnu, Monisankar (2013). "Linking consumption externalities with optimal accumulation of human and physical capital and intergenerational transfers". In: Journal of Economic Theory 148.2, pp. 720-742.

Bishnu, Monisankar and Min Wang (2017). "The Political Intergenerational Welfare State". In: Journal of Economic Dynamics and Control 77, pp. 93-110.

Blanchard, Olivier (Olivier J.) and Stanley. Fischer (1989). Lectures on macroeconomics. MIT Press, p. 650.

Boldrin, Michele and Ana Montes (2005). "The Intergenerational State Education and Pensions". In: Review of Economic Studies 72.3, pp. 651-664.

Boldrin, Michele and Aldo Rustichini (2000). "Political Equilibria with Social Security". In: Review of Economic Dynamics 3.1, pp. 41-78.

Bommier, Antoine et al. (2010). "Who Wins and Who Loses? Public Transfer Accounts for US Generations Born 1850 to 2090". In: Population and Development Review 36, pp. 1-26.

Breyer, Friedrich (1989). "On the Intergenerational Pareto Efficiency of Pay-as-yougo Financed Pension Systems". In: Journal of Institutional and Theoretical Economics 145, pp. 643-658.

Chapman, Bruce (2006). "Chapter 25 Income Contingent Loans for Higher Education: International Reforms". In: Handbook of the Economics of Education 2, pp. 14351503. 
Ciccone, Antonio and Giovanni Peri (2006). "Identifying Human-Capital Externalities: Theory with Applications". In: Review of Economic Studies 73, pp. 381412.

Congressional Budget Office (2013). The Distribution of Federal Spending and Taxes in 2006. Tech. rep.

Cooley, Thomas F. and Jorge Soares (1999). "A Positive Theory of Social Security Based on Reputation". In: The Journal of Political Economy 107.1, pp. 135-160.

Docquier, Frederic, Oliver Paddison, and Pierre Pestieau (2007). "Optimal accumulation in an endogenous growth setting with human capital." In: Journal of Economic Theory 134.1, pp. 361-378.

Friedman, Milton (1962). Capitalism and Freedom. University of Chicago Press, p. 202.

Friedrich, Breyer and Martin Straub (1993). "Welfare effects of unfunded pension systems when labor supply is endogenous." In: Journal of Public Economics 50.1, pp. $77-91$.

Galor, Oded and Joseph Zeira (1993). "Income Distribution and Macroeconomics". In: The Review of Economic Studies 60.1, pp. 35-52.

Kothenburger, Marko and Panu Poutvaara (2006). "Social Security Reform and Investment in Education: Is There Scope for a Pareto Improvement?" In: Economica 73.290, pp. 299-319.

Lange, Fabian and Robert Topel (2004). "The Social Value of Education and Human Capital". In: , Handbook of the Economics of Education 1.1, pp. 459-509.

Lindbeck, Assar and Mats Persson (2003). "The Gains from Pension Reform". In: Journal of Economic Literature 41.1, pp. 74-112.

Miles, David (1999). "Modelling the Impact of Demographic Change upon the Economy". In: The Economic Journal 109.452, pp. 1-36.

Nerlove, Marc (1975). "Some Problems in the Use of Income-contingent Loans for the Finance of Higher Education". In: Journal of Political Economy 83.1, pp. 157-183.

OECD (2007). "Public Sector Pensions and the Challenge of an Ageing Public Service". In: OECD Working Papers on Public Governance.

- (2017a). Education at a Glance 2017. Tech. rep.

- (2017b). Pensions at a Glance 201\%: OECD and G20 Indicators. Tech. rep.

Pogue, Thomas F. and L. G. Sgontz (1977). "Social Security and Investment in Human Capital". In: National Tax Journal 30, pp. 157-169.

Poterba, James M. (2014). "Retirement Security in an Aging Population". In: The American Economic Review 104, pp. 1-30.

Poutvaara, Panu (2004). "Gerontocracy revisited: Unilateral transfer to the young may benefit the middle-aged". In: Journal of Public Economics 88.1-2, pp. 161174. 
Rangel, Antonio (2003). "Forward and Backward Intergenerational Goods: Why Is Social Security Good for the Environment?" In: The American Economic Review 93.3, pp. 813-834.

Richman, Harold A. and Matthew W. Stagner (1986). "Children in an Aging Society: Treasured Resource or Forgotten Minority?" In: Daedalus 115, pp. 171-189.

Rudd, Jeremy (2000). "Empirical Evidence on Human Capital Spillovers". In: Finance and Economics Discussion Series 2000-46 mimeo.

Samuelson, Paul A (1975). "Optimum Social Security in a Life-Cycle Growth Model". In: International Economic Review 16.3, p. 539.

Sinn, Hans-Werner (2000). "Pension Reform and Demographic Crisis: Why a Funded System is Needed and why it is not Needed". In: International Tax and Public Finance 7, pp. 389-410.

Stiglitz, Joseph E and Andrew Weiss (1981). "American Economic Association Credit Rationing in Markets with Imperfect Information Credit Rationing in Markets with Imperfect Information". In: Source: The American Economic Review 71.3, pp. 393-410.

Whiteford, Peter and Edward Whitehouse (2006). "Pension Challenges and Pension Reforms in OECD Countries". In: Oxford Review of Economic Policy 22.1, pp. 7894.

Yamarik, Steven J (2008). "Estimating Returns to Schooling from State-Level Data: A Macro-Mincerian Approach". In: The B.E. Journal of Macroeconomics 8.1, pp. 116. 